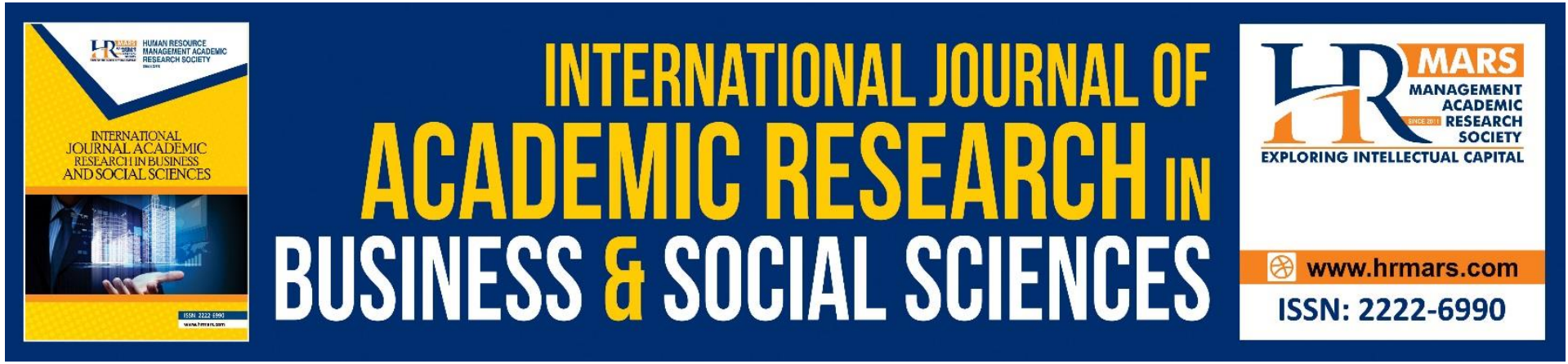

\title{
Adaptations and Negotiating Socio-Political Issues on Painting
}

Jalaini Abu Hassan

To Link this Article: http://dx.doi.org/10.6007/IJARBSS/v11-i9/11033

DOI:10.6007/IJARBSS/v11-i9/11033

Received: 08 July 2021, Revised: 05 August 2021, Accepted: 26 August 2021

Published Online: 11 September 2021

In-Text Citation: (Hassan, 2021)

To Cite this Article: Hassan, J. A. (2021). Adaptations and Negotiating Socio-Political Issues on Painting. International Journal of Academic Research in Business and Social Sciences, 11(9), 502-510.

Copyright: (c) 2021 The Author(s)

Published by Human Resource Management Academic Research Society (www.hrmars.com)

This article is published under the Creative Commons Attribution (CC BY 4.0) license. Anyone may reproduce, distribute, translate and create derivative works of this article (for both commercial and non-commercial purposes), subject to full attribution to the original publication and authors. The full terms of this license may be seen at: http://creativecommons.org/licences/by/4.0/legalcode

Vol. 11, No. 9, 2021, Pg. $502-510$

Full Terms \& Conditions of access and use can be found at http://hrmars.com/index.php/pages/detail/publication-ethics 


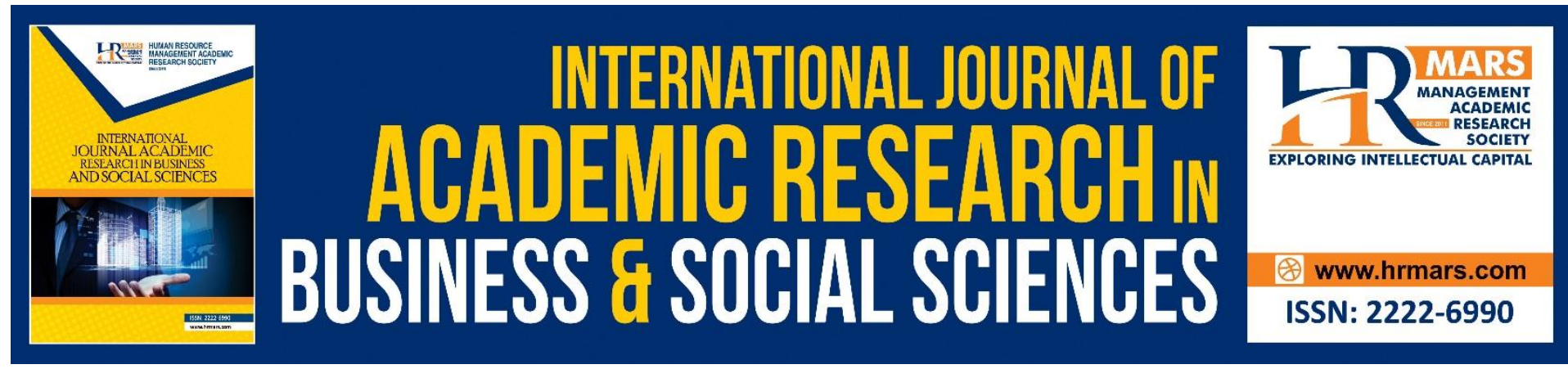

\title{
Adaptations and Negotiating Socio-Political Issues on Painting
}

\author{
Jalaini Abu Hassan \\ Department of Fine Art, Faculty of Art \& Design Universiti Teknologi MARA 40450 Shah Alam \\ Selangor Malaysia \\ Email: Jalai303@uitm.edu.my
}

\begin{abstract}
This project aimed to discuss how the adaptations and negotiating of socio-political issues are discovered in painting throughout creativity and work making. The artistic research supported the whole phases for this project, which begin with the visual analysis, selecting possible imagery and studio logistic for artwork making. The artwork development stimulates different formulation character of the artwork. They have included where the complex socio-political issues have emerged out of the changing socio of our developing nation and region. Therefore, this approach signalling a call for artists to play the voice of conscience or social commentator in their creative work.
\end{abstract}

Keywords: Adaptations, Painting, Socio-Political, Negotiating

\section{Introduction}

In its seventy years of maturing, Malaysian modern art has gone through phases of radical facelifts. Despite a relatively short historical time frame (compared to neighbouring counterparts like Indonesia in the early 1800 s and the Philippines in the sixteenth century), Malaysian art history spans from colonialism in the 1950s to post-independence to MalayIslamic revivalism's socio-political sentiment present in Modern Malaysian art. Since the postcolonial era, artists discuss and celebrate the new changes in the socio-political landscape, and these issues are reflected through their artwork. Arif (1904-1962), one of the Malaysian pioneer watercolourist painters, praises the idyllic kampong scenery for addressing the sense of pride and patriotism to the newly independent nation. He celebrates the wealth of the young country by capturing the dramatic scenery of the mining activity in his 1960 Bumi Bertuah. One of the most visible signs of the changes taking place in the discussion of Malaysian art today can be seen through the massive new interest among the new generation of contemporary artists interested in the socio-political agenda of the country. My investigation is consciously derived from this interest, resulting from the 12th general election of 2008 that triggered the new interest in Malaysian contemporary art practice. This investigation seeks to understand how my artwork corresponds to the significant changes in Malaysia's socio-cultural and political landscape.

Currently, there is an increasing number of contemporary artists who discuss the social-political situation in their artwork, particularly on issues of change and dislocation. The 
artist is Ahmad Shukri, a prolific Malaysian artist who is constructive criticism of spiritual concerns. His clever sense of material and ready-made images was a testimony to his hallmark nature-themed 'Buttnature-themeds' in early 2000. Ahmad Shukri's concern about destroying the natural environment and nature due to deforestation has changed his perception of progress and development. His latest artwork, Golden Gate 2012, investigates the abrupt alteration and destruction in his surrounding due to anthropogenic cause. His new painting, such as 'Dinner with Mr Caribbean' (2011), attempts to warn us of the depletion of nature by presenting us the fragility of natural beauty as a constant reminder of its sacredness. Simultaneously, Shukri value the priceless nature as 'gold' and the 'gate', according to him, is a door toward knowledge. Without knowledge, the soul will be destroyed. The phenomena are a mirror image of man's moral and spiritual degradation, according to Ayman Ahwal (2011), who writes in Shukri's catalogue of an exhibition titled Golden Gate 2012. Another Malaysian contemporary artist is Ahmad Fuad Osman, who deals with the socio-political issue in his artwork. He asks leadership and patriotism and used national history as his strong point of reference to criticize the political war, power abuse and mismanagement that lead to cultural and moral destruction. His historical and socio-cultural references in his artwork strongly reflect the ontological anguish in the context of society. Min Byoung (2005), an art critic from Korea, described Ahmad Fuad's artwork as a strong expressionist style raising a variety of social issues, which lead to the fact that his art lies consistently in the condition of life. The comment confirms Fuad sociological concern in his artwork.

Cultural heroes and warrior such as 'Lang Kacang' (1991) and 'Bujang Berani' (1991) manifest a profound element of ethnicity. The same generation Malaysian artist Bayu Utomo's 'Bujang Berani' 1991 and the recent series of Pahlawan' 2000 reflects the rich ethnicbiographical significance while signalling the silent rage of the warrior. Bayu's artwork reflects his rich ethnographical surrounding by the incorporation of his Javanese culture and Sabahan upbringing. Like Fuad, his artwork represents the anguish of a young man in confronting modern Malaysian society. Yet another example of such social commentary through art is the artwork of Zulkifli Yusof, who in his artwork praises the struggle for independence without bloodshed. At the same time, questioning the role of ethnic supremacy. His profound artwork called Negaraku (2010), exhibited in Balai Seni Visual Negara (National Art Gallery), was an epitome of national patriotism. Social comment and satire are two of the most common methods used by these artists in addressing their concerns. This is due to the social-political situation that leads to the renewed socio interest among the artists, particularly after the nation's 13th general election, as evident from the artwork of the artist mentioned above and other contemporary artists. As a result, artists' interests in political discussions and socioprogress are expressed and discussed openly in today's visual practice.

On the other hand, complex socio-political issues have emerged out of the changing socio fabric of our developing nation and region, signalling a call for artists to play the role of the voice of conscience or social commentator. Nirmala Dutt Shanmughalingam had pioneered the call in the 1970s when she highlighted the issue of war and famine in most of her photomontage artwork. She sees herself first and foremost as an artist, albeit one who has to take a stance against injustice and inhumanity. They need to portray the socio-political drama, especially among contemporary Malay artists, motivating much artistic production, particularly in the middle 21st-century Malaysian modern art scenario. The power of the image and its impact on society cannot be underestimated (Beaumont,1986). According to a popular expression, a picture is worth a thousand words. According to Leavy (2009), this 
saying opens up two of the most paramount issues social researchers consider as they use the visual arts in their knowledge-building practices. The first, visual imagery does not represent the window as suggested by fifteen century's Alberti (De Pictura (1435) Leon Battista Alberti famously instructed painters to consider the frame of the painting as an open window. The authority of visual images is what has made them essentially crucial in our history and the ongoing projection of socio-progress. Secondly, visual art inherently opens up multiple meanings determined not only by the artist but also by the viewer and the context of viewing (both the immediate circumstance and the larger socio-historical context.

\section{Problem Identification}

After the thirteenth general election in 2008, Malaysia's socio-political terrain has gone through a significant shift. The phenomenon triggers a renewed interest in engaging with the socio-political agendas of the nation through my artwork. This is, importantly, a new strategy for me after sixteen years of painting. Unlike my previous artworks, which broadly explore the pop vernacular of Malaysia (life), these new bodies of artwork form a much deeper and sharper critique and commentary on the social changes and dislocation that are taking place in Malaysia. Therefore, they represent a new direction in my quest to question and analyze the (socio) context in which I make my art. The socio-realism approach informs my artworka style I find appropriate to my persistence of storytelling. As a realist style that depicts social injustice, economic hardship and life's struggle, socio realism was a significant artistic movement in the United States in the 1930s. It was originated from American Scene Painting and Regionalism with artists such as Thomas Hart Benton, Edward Hopper and Philip Guston. The term of social realism is in describing the artwork of painters, photographers and filmmakers who draw attention to the everyday conditions of the working classes and the poor and who are critical of the social structures that maintain these conditions (Todd, 2009). As an artist who deals with social realism, my style of investigation was based on the social agenda, human condition, and cultural and historical references. As a result, my artwork is a manifestation of belief, ideology, and value in addressing a specific political agenda and social comment. One can say that Malaysian artists, in general, have become more politically conscious and vocal about what they think and feel as a result of the post-general election in 2008. This characteristic could be traced in our socio-cultural sphere, where artists are taking a much more politically conscious role in shaping their thinking through their artwork. While my body of artworks is not a forced response to this change, they are mainly mimetic and expressive of the cultural life of my surroundings and upbringing. It is only natural that it has influenced my artwork, all painted within a specific time frame.

\section{Significance of the Study}

The whole projects have significantly informed the transformation and dislocation in social and political affair embraced within contemporary art practice. The artworks effectively appropriate an alternative industrial medium of bitumen in reflecting, reconstructing and reinterpreting the Malaysian socio reality. The unique property of the medium conveniently translates the emotional and psychological characteristic within the aesthetic of the artwork. Then, the symbolic approach in painting was systematically strategized and reintroduced in Malaysia contemporary art practice through my body of artworks. This is central in remapping the development of figurative painting in Malaysian contemporary art practice. The inquiry allows me to document my entire process of making systematically. This is a significant 
testimony to the practice-based research, where it will enable my making to be assessed and understood cognitively and visually.

\section{Literature Review}

An overview of the related studies to these projects was discovered from the previous and current studies, where their focus was contributed to the visual art platform. Modern Malaysian art history was formally established when National Art Gallery was formed in 1958. What was initially a modest attempt to house a relatively small collection of Malaysian modern art was later given a significant role to mark the emergence of the historical time frame of Malaysian contemporary art. The early collections see regional works celebrating the idyllic, romantic notion of the Malaysian landscape and largely commemorate the spirit of independence. No propaganda on social and political context was addressed in the works. Not until later in the 1990s, identity, custom and tradition were propagated and towards the end of the decade has led to the more serious content of social issues. After nearly fifty years since the establishment of Balai Seni Lukis Negara (National Art Gallery), Malaysian art has been finally led to relook at modernism. Writers and scholars were intensely discussed and re-evaluate the standard of achievement and direction of Malaysian Modern Art. Vision and Idea exhibition in 1996 was crucial evidence to mark this significant shift. R. Piyadasa, Zabas, Syed Ahmad Jamal, T.K Sabapathy and Kristen Jit were among the influential artists and scholars who discussed the change. Why the rapid change? What transpire it? The overzealous West capitalization of the art, which once claimed to be the hubs of the influential international art scene, has been challenged by globalization wind itself.

On the internal ground, the more intimate affair of racial conflict led to the National Culture Congress in 1971 and was an early reference point in responding to the shift. The realization was important, as it was the first time that social context issues were elevated to a higher level of importance in the artwork (Majid \& Kassim, 2018). Arnold Hauser, Gombrich and others Western thinkers view on the sociological phenomenon on the art was conveniently emphasized. In this new decade, social and cultural content was the most discussed topic among artist of the new generation. From the collective such as Matahati to the younger artists like Saiful Razman, Ise, Boodien, Idham Fadzli to name a few, were among the prolific new talents who look at social reality as the source of the personal statement. However, previously Poshyananda (1996) opening notes on the Traditions/Tensions: Contemporary Art in Asia before the new millennium claims the major force behind the changing wind in the world cultural politic has been the abrupt shift from the traditional EastWest defence axis to the North-South trade axis. In this context, globalization is often seen as either a cultural gain or a challenge to traditional values. Therefore, my artworks are 'forced' to deal with shifting paradigms in politics, economics, religions, and cultures. I am inspired to adapt to the changes and dislocations and change stereotypes and fixities as Poshyananda (1996) viewed. The dislocation in Asia in the nineties have resulted in anxiety, disorientation, and cultural dysfunction in capitals and megacities where cultural heritage and tradition are under threat. The body has become a symbol of both the self and the masses, anxiety and relief, sacredness and profanity, violator and victim. The preservation of traditional, national, regional, ethnic and religious allegiances has become a way for artists to express nostalgia or resistance to the 'poisonous' West. But the shift to the Eastern philosophy in the Malaysia context probably intensified during the Mahathir era of 'Look East' in the late 80s paired with Anuar Ibrahim's in national Islamisation. 
The concept of transformation has been a primary agenda in social, political and economic affair embraced within contemporary art practice (Wan \& Sirat, 2018). It was no coincidence that the phenomenon was signified by the historic meeting between Chinese leader Deng Xiaoping and Indian Prime Minister Rajiv Gandhi in 1988 (Garver, 1992). The event symbolizes a belief that the East will dominate the twenty-first century. The international art world has predicted these geopolitical changes. In museums and galleries around the world, observers of contemporary art today will more than likely witness pieces by Asian artists (Harris, 2011). When a renowned Japanese artist Takashi Murakami (b. 1962), collaborated his work with luxury brand Louis Vuitton in 2002, he was voted one of Time Magazine's hundred most influential people. In that same year, Chinese artist Cia Guo-Qiang (b. 1957) had a retrospective at New York's Guggemhiem Museum. Asian artist is now featured at world-survey exhibitions such as documentation and the Venice Biennale as well as the prominent private galleries in America and Europe.

\section{Studio-Practiced}

The body of artworks was developed throughout this project, which focuses on Chanang (2008); Menjerit (2009); Dendongeng (2010); Bangsawan Kebangsawan (2011); Siang \& Malay (2015).

\section{Validation of Inquiry}

Art making is examined as a form of inquiry into theorizes, practices, and contexts used by artists: The critical and creative investigation that occurs in the studio is a form of research grounded in art practice (Sullivan, 2004). This, according to Jones (2006), a kind of validation requires in art-based inquiry. The evaluation generated including a critical investigation of the craft and the aesthetic of artistic practice, a creative examination of how art evokes responses and connection, and a careful inquiry into the method that art uses to unsettle ossified thinking and provoke imagination (Leggo, 2008). It is an inquiry that includes a conscientious consideration of the resonances that sing out to the world, image, sound and performance (Sinner et al., 2006).

\section{Thematic Discourse}

My work corresponds to Malaysia's changing cosmological culture in an attempt to investigate through bodies of work, the adaptation of changes, compromising tolerances and confronting status quo within the socio-cultural atmosphere of post-colonial Malay Visual Culture. The investigation brings about series of painting that demonstrates, within the context, the challenges encountered alongside the compelling shift in both style and content. I am inquiring about how my work describes, interprets, and informs the current sociopolitical phenomena that significantly alter the socio-cultural terrain of the country. The alteration has impacted my creative practice through series of new body of work. They reflect the new developing theme, innovative medium exploration and application that lead to new and various stylistic approaches. The thematic development came across in the wake of the 2008 Malaysia's general election where there is a renewed interest in engaging with the sociopolitical agendas of the nation through art.

\section{Entry Point}

In reflecting the issue of changes that taking place in social-political landscape in Malaysia that impacted the body of my work, I choose to strategize the series into three thematic 
series. Chanang (2008); Menjerit (2009); Bangsawan Kebangsaan (2010). They were conveniently transpired by socio-political occurrence in Malaysia particularly after the 12th General Election in 2008 that contributes a significant alteration toward the development of Malaysian art. The phenomenon leads to artists' renewed interests in political dialogue and socio progress expressed and discussed openly in today's visual practice. While this new interest is not uncommon in the field of visual art, the specificity of narrative is explored within my work in three thematic plots.

\section{Studio Inquiry}

The necessary insanity of studio, and points out that a year's long spent in a studio can make an artist into a treasury of almost incommunicable knowledge about the unique properties of the material and his improvised production method. In my studio process, bitumen and other industrial materials such as polyurethane, shellac, polymer and water-based asphaltum are extensively used for the past ten years. Extensive knowledge on the sophistication of the medium and its intrinsic characteristic is ultimately embedded within my practical skill. Studio journal becomes my written exposition of the narrative of my art making. It casually indicates the progress and type of narrative used in the process of developing the body of artworks.

\section{Permissible Entry}

The permissibility became the issue that I was initially concerned most. Here, I wanted to make reference to the structure that polices an image's appropriateness and therefore also its context, meaning and significance (Condom and Cow, 2007). The project of Halal (2007) allows me to explore the taboo subjects within the discourse of permissibility, questioning the boundaries of its inclusiveness. The question I asked were: What is appropriate, what is permissible and what is good? I wanted to explore this issue not just on the surface level of iconography but also by tackling the question of what is an appropriate style. Figuration is by large viewed as taboo according to socio-convention of Malay values and principles much more than Islamic universal teaching.

\section{The Ontology of Studio}

from Concept to Concrete - The artist's studio is a subject that has been studied in many different ways from the history, to physical function, its intimacy and pedagogic. Amongst the literatures were Michael Wayne Cole's Invention of the Studio, Renaissance to Romantics produced. Some investigates the range of studio's atmosphere of a specific time in specific place while others raise questions about the relationship between studio practices and their wider political, economic and cultural context. The crucial aspect however, that most literatures did not elaborate is the complex, didactical relationship its inhabitant has with this sacred space. As an artist, my studio is my practical domain comprised of practical skill, knowledge and experimentation. The mutual cooperation between the space and me is fundamentally important. The practical knowledge imparted within my creative process in interdependent/inter-reliant with the physical nature of my studio in Figure 1 and Figure 2. 


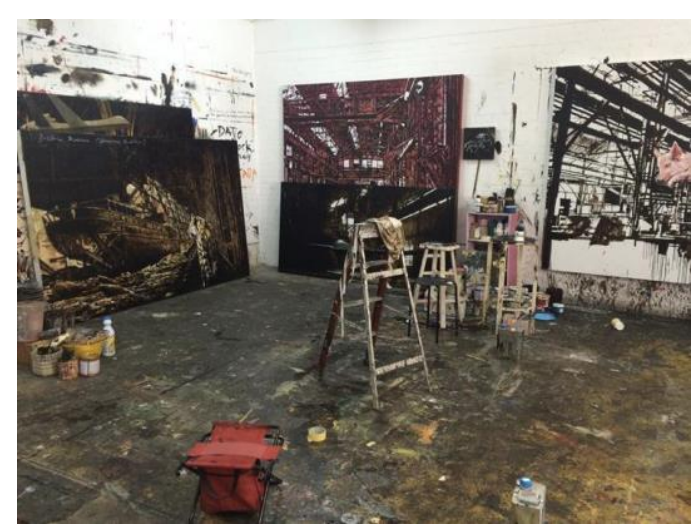

Figure 1: The nature of studio

\section{Studio Dialogue}

The intimate relationship and understanding artist has with his material is didactic and mysterious. There is a constant dialogue between these two parties that requires specific mutual ground. Life spent on understanding the property of materials and how they work is the fundamental fact ignored by most historians. Painters watch their paints very closely to understand what they can do in their fullest potential. How the paint transmutes to images is a mystery they themselves fascinate with. It is no wonder that painters can be so entranced by materials they work. Every marks, strokes and effects can become eloquent records of painter's activities, feelings and moods. Paint incites emotions and other wordless experience.

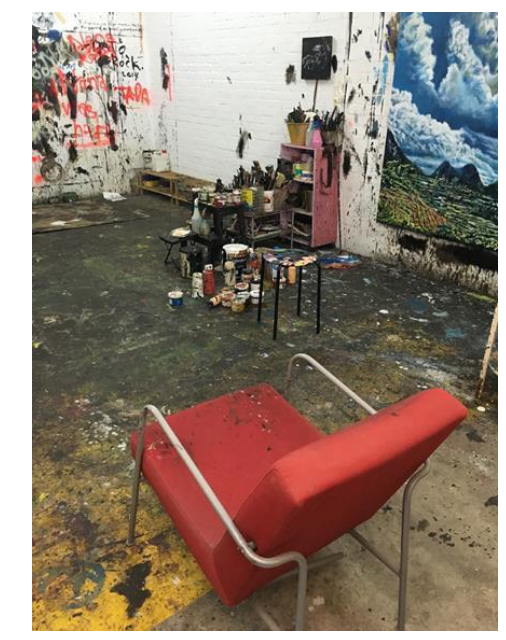

Figure 2 : Creative process and making artwork.

\section{Conclusion}

To sum up, the project clearly defined the formulation of artwok was interact with sociopolitical elements throughout the processes of creative research work making. The whole phases for this project, which begin with the visual analysis, selecting possible imagery and studio logistic for artwork making. The artwork expansion motivates in formulation different character of artwork. The idea encompassed where the complex socio-political materialized and emmbedded in their nation and region via creativty. Indeed, the artistic research was able to indicating to all creative practices shared their voice on social commentator. 


\section{References}

Elkins, J. (2002) Stories of Art. New York: Routledge.

Elkins, J. (2003) Visual Studies: A Sceptical Introduction. London: Routledge. Bell, J. (1999) What Is Painting? London: Themes and Hudson

McNiff, S. (2009) Art-Based Research. Philadelphia: Jessica Kingley Publishers.

Grierson, E., \& Brearley, L. (2009) Creative Art Research: Narratives of Methodologies and Practices. Rotterdam: Sense Publishers.

Rose, G. (2007) Visual Methodologies: An Introduction to the Interpretation of Visual Materials. Second Edition. London: SAGE Publications.

Beaumont, M. R. (1986). Contemporary Art in Malaysia. Art Monthly (Archive: 1976-2005), (101), 20.

Poshyananda, A. (1996). Contemporary art in Asia: traditions, tensions. Asia Society. Garver, J. W. (1992). China and South Asia. The ANNALS of the American Academy of

Political and Social Science, 519(1), 67-85.

Harris, J. (Ed.). (2011). Globalization and contemporary art. John Wiley \& Sons.

Majid, N. H. A., \& Kassim, S. J. (2018). Monumentalising the Vernacular: Criticality, Culture and Identity of the City. In Modernity, Nation and Urban-Architectural Form (pp. 7999). Palgrave Macmillan, Cham.

Wan, C. D., \& Sirat, M. (2018). The development of Malaysian higher education: Making sense of the nation-building agenda in the globalization era. Asian Education and Development Studies, 7(2), 144-156. 